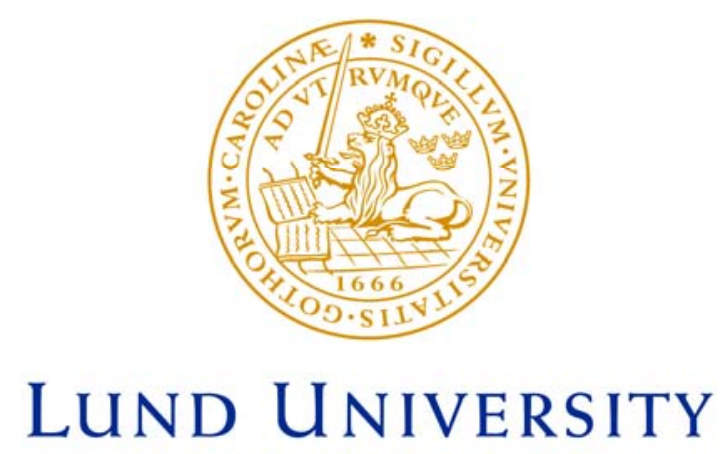

Faculty of Medicine

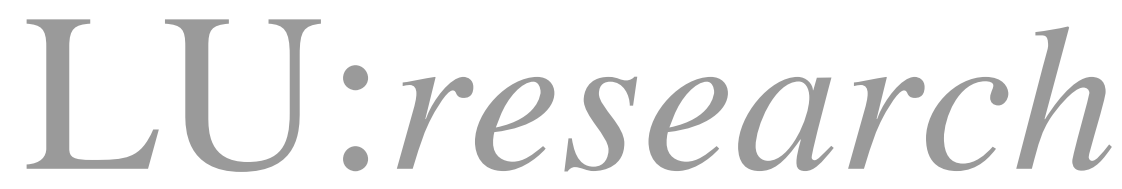

Institutional Repository of Lund University

This is an author produced version of a paper published in Clinical nutrition. This paper has been peer-reviewed but does not include the final publisher proof-corrections or journal pagination.

Citation for the published paper:

Hommel, Ami and Bjorkelund, Karin B and Thorngren, Karl-Göran and Ulander, Kerstin

"Nutritional status among patients with hip fracture in relation to pressure ulcers."

Clin Nutr, 2007, Vol: 26, Issue: 5, pp. 589-596.

http://dx.doi.org/10.1016/j.clnu.2007.06.003

Access to the published version may

require journal subscription.

Published with permission from: Elsevier 


\title{
NUTRITIONAL STATUS AMONG PATIENTS WITH HIP FRACTURE IN RELATION TO PRESSURE ULCERS
}

\author{
Ami Hommel ${ }^{1,2}$, Karin B Bjorkelund ${ }^{1}$, Karl-Göran Thorngren, ${ }^{2}$ Kerstin \\ Ulander, ${ }^{3}$
}

From the ${ }^{1}$ Department of Health Sciences, Lund University, P.O. Box 157, SE22100 Lund, Sweden; the ${ }^{2}$ Department of Orthopedics, Lund University Hospital, SE-221 85 Lund, Sweden, and the ${ }^{3}$ Department of Health Sciences, Kristianstad University, SE-291 88 Kristianstad, Sweden

\section{ABSTRACT}

Background \& Aims: Patients with a hip fracture often have a poor nutritional status which is associated with increased risk of complications, morbidity and mortality. The aim of this study was to investigate the effects of an improved care intervention in relation to nutritional status and pressure ulcers. An intervention of best practices for patients with hip fracture was introduced, using the available resources effectively and efficiently with a not too complicated or expensive intervention.

Methods: A quasi-experimental study of 478 patients consecutively included between April $1^{\text {st }} 2003$ and March $31^{\text {st }} 2004$. A new evidence based clinical pathway was introduced on October $1^{\text {st }} 2003$. The results from the first 210 patients in the control group and the last 210 patients in the intervention group are presented in this article.

Results: The total number of patients with a hospital acquired pressure ulcer was in the intervention group, 19 patients, and in the control group 39 patients $(\mathrm{p}=0.007)$. No patient younger than 65 years developed a pressure ulcer. There were no statistical significant differences between the groups with respect to blood biochemical variables at inclusion. Patients in the control group had higher arm muscle circumference (AMC) $(p=0.05)$, calf circumference $(\mathrm{CC})(\mathrm{p}=0.038)$ and body mass index $(\mathrm{BMI})(\mathrm{p}=0.043)$ values. Abnormal anthropometrical tests of BMI, triceps skin fold (TSF) $<10^{\text {th }}$ percentile and AMC $<10^{\text {th }}$ percentile were found in 12 patients in the control group and in 4 patients in the intervention group. None of the four patients in the intervention group developed pressure ulcers. However two of the 12patients in the control group were affected.

Conclusions:

It is possible to reduce the development of hospital acquired pressure ulcers among elderly patients with a hip fracture even though they have poor prefracture nutritional status. The results in this study indicate the value of the new clinical pathway, as the number of patients who have developed pressure ulcers during their stay in hospital has been reduced by $50 \%$.

KEYWORDS: Hip fracture, pressure ulcers, nutritional status

Correspondence to: Corrrespondence to: Ami Hommel, Department of Orthopaedics, Lund University Hospital, SE-221 85, Lund, Sweden. Tel,:+4646177106; fax +4646172165. E.mail address: Ami.Hommel@med.lu.se 


\section{INTRODUCTION}

Despite a growing awareness of the dramatic impact on quality of life and treatment $\operatorname{costs}^{1,2}$ the occurrence of pressure ulcers (PU) is still an abundant problem among hip fracture patients. Patients with a hip fracture often have a poor nutritional status ${ }^{3}$ which is associated with increased risk of complications, morbidity and mortality ${ }^{4-8}$. Especially protein energy malnutrition (PEM) which is an important determinant of clinical outcome, is seen more often in patients with a hip fracture than in age-matched control subjects ${ }^{3,8.9}$. Carpintero ${ }^{10}$ noted higher mortality in men than in women with hip fracture related to nutritional status. Patients with a hip fracture may also have poor food intake in hospital ${ }^{11}$. Adequate nutrition is essential in the care of the hip fracture patients in order to achieve recovery without complications.

The aim of this study was to investigate the effects of an improved care intervention in relation to nutritional status and PUs, a care intervention of best practices for patients with hip fracture ${ }^{12}$, not too complicated or expensive, but only using the available resources effectively and efficiently.

\section{METHODS}

The study was conducted at the University Hospital in Lund, Sweden. The subjects were 478 patients with a hip fracture consecutively included between April $1^{\text {st }} 2003$ and March $31^{\text {st }} 2004$. On October 12003 a new evidence based clinical pathway was introduced. The transition period for implementing the new pathway was 44 days and the 58 patients from this period are not included here. Comparisons are here made between the 210 first patients in the control group (CG) and the 210 last patients in the intervention group (IG), to reduce confounding factors from the transition period. Six patients in the CG and five patients in the IG had PU at admission, and these PU are excluded from the analyses. Two of the patients in the IG suffered a fracture on the opposite hip during hospitalization due to a new fall which prolonged their hospitalization and these patients were not included anew.

Written informed consent was obtained from all lucid patients before entering the study. Not lucid patients were included after permission from there next of kin. The study was approved by the Ethics Committee of the Medical faculty of Lund University (LU 39-03) and has been performed in accordance with the declaration of Helsinki.

At the University hospital patients with a hip fracture are intended to be treated at one of the three orthopaedic wards with totally 64 beds. However due to the bed situation patients with a hip fracture could be treated wherever there was a bed available at the hospital the moment the patients were admitted to the Acute 
and Emergency (A\&E). When a patient was treated at a non-orthopaedic ward the personnel at this ward was supervised by an orthopaedic surgeon. The care personnel were always welcome to phone the orthopaedic wards if they would have any questions about the care of the patient. Patients treated at other departments were in the CG 71, respectively 76 in the IG. Regardless of which type of ward the patients were treated on, the patients in the CG followed the intended clinical pathway used before the intervention and the patient in the IG followed the new evidence based clinical pathway.

Spinal anaesthesia was administrated to $70 \%$ of the patients and general anaesthesia to $30 \%$ of the patients. All patients underwent anticoagulation prophylaxis with low-molecular-weight heparin for approximately 10 days postoperatively.

All patients at risk of developing PU were placed on pressure relief mattresses. For patients with a high risk of developing PU an alternating pressure relief mattress was used.

All patients' demographic data were registered in the Swedish national quality register RIKSHÖFT. All patients undergoing surgery are routinely examined before surgery by an anaesthetist who assesses the patient's physical status using the American Society of Anaesthesiologists classification of physical status (ASA). The ASA grade is included in the RIKSHÖFT registration.

\section{Data collection}

Two doctoral students, clinical nurse specialists in orthopaedic (AH) and anaesthesia (KBB), were responsible for the study performance. They included the patients, collected all data and were available 24 hours a day, seven days a week, during the study period.

When a patient with a suspected hip fracture arrived to the A\&E she/he was tested within 30 minutes for lucidity with the Short Portable Mental Status Questionnaire (SPMSQ) ${ }^{13}$. To find patients at risk of developing pressure ulcers the Braden scale ${ }^{14}$ was used for both groups. The modified Norton scale ${ }^{15}$ was in addition used solely for the IG.

Pressure ulcers were classified according to the European Pressure Ulcer Advisory Panel's (EPUAP) classification ${ }^{16}$ (Table 1). The patients' skin was observed daily from the arrival to hospital until discharge, and followed up with home visits after four and twelve months. During the transition period the 
personnel were educated in how to use the modified Norton scale and their results were compared with the study nurses as learning assessment

\section{Nutritional assessment}

Nutritional assessment for all patients consisted of laboratory testing (Table 2) taken at the A\&E, a questionnaire about food consumption and weight changes and anthropometry which was performed five days after surgery. The standard laboratory SS-EN ISO/IEC 17025 was used at the hospital for all biochemical tests.

If the patient was unable to answer the questions about food habits, a proxy (a relative or staff from the patient's home) answered if possible. With the patients wearing light clothing body weight was measured in the morning, to the nearest $0,1 \mathrm{~kg}$ on a digital wheelchair scale (Umedica BWB 620 ) at the University hospital. Patients transferred before day five to the local hospital were measured on an ordinary wheel-chair scale at that hospital. A portable scale (Philip MP5325) was used at home visits at four and twelve months after surgery. The digital wheelchair scale was regularly checked for accuracy. The portable scale was used to calibrate all scales.

Patients' height was measured in a supine position on a flat bed, as only few patients were able to stand independently. A BMI of $<20 \mathrm{~kg} / \mathrm{m}^{2}$ was considered as underweight if the patient was $<70$ year and BMI of $<22 \mathrm{~kg} / \mathrm{m}^{2}$ was considered as underweight if the patient was $>70$ years ${ }^{17-19}$. Mid-arm circumference (MAC) was measured with a flexible non-stretch tape on the nondominant upper arm. Posterior on the same arm midway between the acromion and olecranon triceps skin fold thickness (TSF) was measured with a Harpenden calliper. The mean of three readings was used. Comparison of AH's and KBB's anthropometric measurements were regularly checked for reliability. To calculate arm muscle circumference (AMC) the formula AMC $=$ MAC- $0,1(\pi$ *TSF) was used. Values of TSF and AMC were considered subnormal if they were equal or below the $10^{\text {th }}$ percentile in a Swedish reference population ${ }^{20}$.

\section{Intervention}

The evidence based pathway in the intervention consisted of: Giving three litres of oxygen/minute preoperatively starting in the ambulance and the first days postoperatively, intravenous supplementation (glucose liquid) starting in the ambulance, intravenous pain relief at the A\&E. Routines were changed so that the patients did not have to return to the A\&E following x-ray; instead they were transported directly to the orthopaedic ward. The use of pressure relief was 
emphasised to all staff and alternating pressure mattresses were used more frequently. Furthermore the patients were supposed to be given a higher priority on the surgery waiting list. The patients' saturation level was measured at least twice a day pre- and postoperatively and a special nutritional drink given twice a day postoperatively. This milk-tasting drink with $125 \mathrm{kcal} / 100 \mathrm{mlwas}$ enriched with arginine, zinc, vitamins $\mathrm{A}, \mathrm{B}, \mathrm{C}$ and $\mathrm{E}$, and other antioxidants such as selenium and carotenoids to enhance wound healing and control inflammation.

\section{Statistics}

Differences between groups were measured using Fisher's Exact test (categorical data) and Student T-test (continuous data). For analyses the Swedish Hip fracture register SAHFE.reg.exe and the Statistical package for the Social Sciences (SPSS, Inc, 444 N Michigan Avenue, Chicago IL, USA) version 14.0 for windows was used. A P-value $<0.05$ was considered significant.

\section{RESULTS}

\section{Patient characteristics}

There was no significant differences between the groups with regard to age, sex, lucidity, smoking, ASA-grade, hip fracture type, time to operation, time on operation -table, pre-fracture living conditions, length of stay at hospital or mortality (Table, 3). However the co-morbidity was higher in the intervention group. At admission $36 \%$ of the patients in the IG had a diagnosis of three or more diseases, versus $20 \%(\mathrm{p}=0.003)$ of the patients in the CG.

\section{Biochemical variables}

There were no significant differences between the groups with respect to biochemical variables at inclusion. The level of C-reactive protein (CRP), which is an acute face protein produced in response to microbial invasion, tissue injury, immunological reactions and inflammatory reactions were enhanced in more than half of all patients. Among these patients, $14 \%$ had a urinary tract infection. Forty patients (19\%) in the CG and 34 patients $(16.2 \%)$ in the IG had abnormal values in s-albumin as well as s-transthyretin at inclusion indicating risk for malnutrition. On day five patients in the IG had significantly higher 
sodium value ( $p=0.005)$. After four months patients in the $\mathrm{CG}$ had a significant higher transthyretin value $(\mathrm{p}<0.001)$.

\section{Anthropometrical variables}

At baseline a BMI of $<20 \mathrm{~kg} / \mathrm{m}^{2}$ in patients $<70$ year and BMI of $<22 \mathrm{~kg} / \mathrm{m}^{2}$ in patients 70 year or older was found in $24,8 \%$ in the CG and $32.9 \%$ in the IG calculated on 197 respectively 194 patients. Patients in the CG had higher AMC $(p=0.05), C C(p=0.038)$ and BMI $(p=0.43)$ values. Also at 12 months follow up the CG had higher BMI ( $\mathrm{p}=0.021)$ compared with the IG (Table 4). TSF and AMC were measured in 197 patients in the CG and in 204 patients in the IG. Abnormal nutritional parameters when using TSF $<10^{\text {th }}$ percentile was present in $36(18.3 \%)$ patients in the CG and in $40(19.6)$ patients in the IG. Of these 21 patients in the CG versus 23 patients in the IG had TSF values $<5^{\text {th }}$ percentile indicating severely malnutrition ${ }^{20}$. Nineteen patients $(9 \%)$ in the CG and 22 $(10.5 \%)$ patients in the IG had AMC $<10^{\text {th }}$ percentile. Abnormal anthropometrical tests of BMI, TSF $<10^{\text {th }}$ percentile and AMC $<10^{\text {th }}$ percentile were found in 12 patients in the CG and in 4 patients in the IG.

No weight loss within the last three months was found in $47.6 \%$ of 210 patients in the CG and in $58.1 \%$ of 208 patients in the IG. It was $27.6 \%$ of the patients in the CG who did not know if they had had a weight loss compared to $32.4 \%$ of the patients in the IG. The number of patients that had lost weight was $14.8 \%$ in the CG and $5.8 \%$ in the IG. Weight gain was found in $10 \%$ of the patients in the $\mathrm{CG}$ and in $2.9 \%$ in the IG:

\section{Pressure ulcers}

In total there was the same amount of pressure ulcers (8) in both groups at admission. The PU was noted on six patients in the CG and on five patients in the IG.. At discharge 13 of 420 patients had developed two pressure ulcers each and one patient had developed three pressure ulcers. At discharge the total amount of pressure ulcers were 50 ulcers on 43 patients in the CG and 28 pressure ulcers on 21 patients in the IG $(\mathrm{p}=0.009)$ (Table 5).

The total number of patients with a hospital acquired pressure ulcer was in the CG, 39 patients and in the IG, 19 patients, $(p=0.007)$. Of the patients treated at other departments which was 71 patients in the CG, nine patients (12.7) developed PU compared to eight of the 76 (10.5) in the IG.

Two of the twelve patients in the CG with abnormal anthropometrical tests of BMI, TSF $<10^{\text {th }}$ percentile and AMC $<10^{\text {th }}$ percentile developed pressure 
ulcers. One of these patients developed grade I ulcers at sacrum and on a heel, and the other patient developed a grade II ulcer at sacrum. However none of the four patients in the IG were affected.

None of the 33 patients who were under 65 years of age developed PUs in either group. Among patients aged 65 to 74 years (53 patients) there were only three $(1.4 \%)$ respectively $2(1 \%)$ that developed PUs. In patients older than 85 years, $65.5 \%$ of all PUs developed. The incidence of pressure ulcers in the intervention group was half of the incidence of same age in the control group.

None of the three patients who were on the operation table $<60$ minutes developed a pressure ulcer. Five of 51 patients $(9.8 \%)$ with time on operation table between $61-90$ minutes and 53 out of 362 patients (14.6\%) with more than 90 minutes on the operation table developed pressure ulcers.

Patients with SPMSQ score between 0-7 indicating dementia or confusion developed statistical significantly more PUs than lucid patients. In the CG was it 22 out of 81 patients $(\mathrm{p}=0.017)$ with SPMSQ score $=7$ that developed a PU compared to 12 out of 74 patients $(\mathrm{p}=0.011)$ in the IG. However no significant reduction of PUs was noted in the IG among not lucid patients. Of these 36 patient, was it one patient in the CG and one patient in the IG who had signs of undernutrition with abnormal anthropometrical tests of BMI, TSF $<10^{\text {th }}$ percentile and $\mathrm{AMC}<10^{\text {th }}$ percentile concurrent. There were significantly $(p<0.001)$ more patients among not lucid patients with contemporary low levels of s-albumin and s-transthyretin at admission to hospital.

\section{DISCUSSION}

Although there is awareness that malnutrition must be recognized, there are no golden standard of a screening system assessing nutritional status and no consensus regarding absolute criteria for malnutrition. In this study we used a sample of biomedical and anthropometric variables together with a questionnaire. Hedströms et al. $^{21}$ stated, that patients with a hip fracture in general have a low body mass index (BMI), and low biochemical nutritional markers on admission to hospital, signs that indicate malnutrition which the results of the study presented in this paper confirms.

There were no significant differences between the groups with respect to biochemical variables at inclusion. Low values in s-albumin as well as stransthyretin at inclusion indicating malnutrition were present in $14.8 \%$ of all patients. Low levels of s-transthyretin at inclusion and at four month were found in 19 patients in the CG and in 31 patients in the IG. The low level of s-albumin (half life of 20 days) may be a result of dehydration as a result of poor liquid and 
food intake. On day five, patients in the IG had significantly higher sodium $(\mathrm{p}=0.005)$ which may depend on the intravenous supplementation they received which started already in the ambulance resulting in not dehydrated patients before surgery.

We chose to measure BMI, total arm length, MAC, TSF, AMC, CC and knee height on day five to se if there were any significant differences between the groups that would explain the significant differences of developing PUs. BMI assessment was repeated at discharge, at four months and after 12 months. These anthropometric parameters were chosen because they can be measured with a minimum of equipment and time. Not all measurements could be undertaken on all patients because of the patient's condition. We asked the patients if they had gained or loosed weight within the last three months. Since more than one third of the patients have dementia or confusion it was difficult to get a correct answer on questions like this. Still we think that it is important to include patients with dementia which is confirmed by Huusko ${ }^{22}$ and Rolland ${ }^{23}$. It was $14.8 \%$ of the patients in the CG respectively $5.8 \%$ of the patients in the IG that stated weight loss. Since weight loss express a process this may be an important indicator of undernutrition. Weight loss is most often caused by reduced food intake. Cognitive impairment is an important risk factor for weight loss and undernutrition $^{24}$ since the patients can not meet nutritional needs and therefore are more vulnerable.

BMI is a well adopted tool for detection of malnutrition in elderly individuals but due to kyphoscoliosis, deformities and the difference in individual height loss with ageing the measurements of height may limit $\mathrm{BMI}^{25}$. In this study when using low BMI as the only anthropometric measure of nutritional status calculated on 197 respectively 194 patients, $24.8 \%$ of the patients (52) in the CG and $32.9 \%$ of the patients (69) in the IG were undernourished. Combining low levels of BMI with TSF $<10^{\text {th }}$ percentile and AMC $<10^{\text {th }}$ percentile as indicating malnutrition were present in 12 patients in the $C G$ and in 4 patients in the IG. These differences shows the needs for caution when only using BMI as an indicator of undernutrition.

Additional nutrition has previously been tested. Houwing ${ }^{6}$ included 103 patients with a hip fracture in a randomized controlled trial (RCT). The patients received $400 \mathrm{ml}$ daily of a supplement enriched with protein, argine, zinc and oxidants $(n=51)$ or a non caloric water-based placebo supplement $(n=52)$ in between their regular meals. The supplementation of food started directly postoperatively for a period of four weeks or until discharge. The PU development between the RCTgroups was not significantly different but the incidence of PUs stage II showed $9 \%$ difference between supplement (18\%) and placebo (28\%). 
In our intervention study we used a gluten free milk-tasting drink for the dietary management of pressure ulcers. All patients were offered two drinks every day while hospitalised. Compliance was quite good, however not every one liked the drinks but we were able to persuade all patients to drink at least one a day (200 $\mathrm{ml}$ ). According to the records ten patients did not drink two drinks a day, nine of them did not develop any PU. In this study the PUs were mostly of grade 2 in the CG and mostly of grade 1 in the IG and there is a significant difference in development of PUs $(p=0.007)$ between the groups. This seems to indicate the importance of the intervention. Patients treated at other departments did not have a significant reduction of PU, which may depend on missed diagnosis of PUs in these patients, both in the CG and the IG. At the orthopaedic department all staff was well trained and understood the importance of diagnosing even PU grade 1.

Patients mostly develop PU of grade I according to Houwing ${ }^{6}$. Reed ${ }^{26}$ did a cohort study with 2,771 patients at 47 hospitals and found that 14,7\% developed at least one stage II or greater PU over a two week period. Confusion was a statistically significant risk factor. In this study 155 (36.9\%) patients were not lucid on arrival at the hospital and $34(22 \%)$ of them developed pressure ulcer compared to 24 out of 265 (9\%) lucid patients. We believed that these findings could be explained by the longer waiting time for surgery in the group of not lucid patient. But we could not find any significant explanation regarding waiting time. Patients classified as lucid on arrival waited for an average of 26.9 hours to come to the surgery compared to 26.8 hours in the group of not lucid patients. However more of them had signs of undernutrition at admission to hospital. They might also rest differently on the bed with less awareness of the importance of small changes of position.

Risk factors of PU development in patients undergoing surgery have been identified by a multiple stepwise regression analyses by Lindgren et al. ${ }^{27}$. One risk factor in their 286 patients was a high score in the sickness classification according to American Society of Anesthesiologists (ASA). In this study ASA classification showed no significant difference between the groups. However the co-morbidity was significantly higher in the IG. This was not due to better recording of the patients in the IG since all patients demographic data were registered in the Swedish national quality register RIKSHÖFT and furthermore all medical journals were checked to assure this. In the CG $60.5 \%$ of the patients were classified as ASA class I or II compared to $54.3 \%$ in the IG. No patient with ASA classification 1 (healthy) developed a PU. It was 38 patients in ASA classification 3 and 4 who developed pressure ulcers.

According to Houwing ${ }^{28}$ risk factors for developing PUs in patients with a hip fracture are high age and increased length of time on the operating table. In this study high age was a risk factor but not prolonged stay at the operating table. 
That may be explained by good pressure relief mattresses on the operating table introduced several years ago.

It is well known that malnutrition is associated with an increased risk of complications in patients with a hip fracture ${ }^{7,8,28}$ and intervention trials have reported positive effects of lean body mass, ADL and health related quality of life $^{29}$ and long term complications ${ }^{30}$. Malnutrition is still a challenge for health care, since evidence based practise has not yet been implemented and more research is needed to find efficient and easy ways to optimize nutritional status pre- and post operatively in patients with hip fractures.

The result in this study indicates the importance of the new clinical pathway introduced, as the number of patients who have developed pressure ulcers during their stay in hospital has been reduced by $50 \%$ even though more patients in the IG had signs of under nutrition at admission.

\section{Limitations of the study}

This study has limitations. First we did not design the study as a randomized controlled study which is accepted as being the most reliable method for assessing effectiveness. We selected a quasi experimental design for two reasons. The first reason was that the intervention started already in the ambulance and since five different ambulance stations were involved, we couldn't assure that patients were randomized and cared for in a proper way. The second reason was that even if we had tested the intervention at only a few of the ambulance stations, we would have created a large problem at the University hospital due to the bed situation. There is a great risk of confounding if the staff should give different treatment to a patient group with the same diagnoses which could hazard the results. Furthermore even if the barriers

presented had not been there, the ethical issue of not treating patients with the best practice was an important reason not to randomize.

\section{Acknowledgements}

We wish to thank all patients included in the study. All staff involved in this study at the University Hospital, the local hospital and at all the different homes for elderly people is gratefully acknowledged for their help in conducting this study. The study was supported by the Swedish National Board of Health and Welfare and the Swedish Association of County Councils. 


\section{Funding}

The Swedish National Board of Health and Welfare and the Swedish Association of County Councils.

\section{Authorship}

$\mathrm{AH}, \mathrm{K} \mathrm{B}-\mathrm{B}, \mathrm{K}-\mathrm{G} \mathrm{T}$ and $\mathrm{KU}$ conceived this study. AH and K B-B performed the study. AH, K-G T and KU contributed to data analysis and writing of the paper

\section{Conflict of interest}

None known. 


\section{REFERENCES}

Allman RM. Pressure ulcer prevalence, incidence, risk factors, and impact. Clin Geriatr Med 1997 Aug;13(3):421-36

Barczack CA, Barnett RI, Childs EJ, Bosley LM. Fourth national pressure ulcer prevalence survey. Adv Wound Care 1997 Jul-Aug;10(4):18-26

Bastow MD, Rawling J, Allison SP. Undernutrition, hypothermia, and injury in elderly women with fractured femur: an injury response to altered metabolism? Lancet 1983;1 (8317)143-146

Herrmann FR, Safran C, Lekoff SE, MInaker KL. Serum albumin level on admission to as a predictor of death, length of stay, and readmission. Arch Int Med 1992;152:125-130

Patterson BM, Cornell CN, Carbone B, Levine B, Chapman D. Protein depletion and metabolic stress in elderly patients who have a fracture of the hip. $\mathrm{J}$ Bone Jt Surg (Am). 1992;74:251-260

Houwing, RH., Rozendaal, M., Wouters-Wesseling, W., Beulens, JWJ. Buskens, E. \& Haalboom. JR. (2003). A randomised double-blind assessment of the effect of nutritional supplementation on the prevention of pressure ulcers in hip fracture patients. Clin Nutr 2003; 22 (4):401-405

Ponzer S, Tidermark J, Brismar K, Söderqvist A, Cederholm T. Nutritional status, insulin-like growth factor-1 and quality of life in elderly women with hip fractures. Clin Nutr 1999; 18: 241-246

Lumbers, M., New, SA., Gibson, S \& Murphy, MC. Nutritional status in elderly female hip fracture patients: comparison with an age-matched home living group attending day centres. Br J Nutr 2001; 85: 733-740

Galvard H, Elmståhl S, Elmståhl B, Samuelsson SM, Robertsson E. Differences in body composition between female geriatric hip fracture patients and healthy controls: body fat is more important as explanatory factor for the fracture than body weight and lean body mass. Aging (Milano) 1996; 4: 282-286

Carpintero P, Lopez P, Leon F, Liuch M, Montero M, Aguilera C. Men with hip fracture have poorer nutritional status and survival than women; a prospective study of 165 patients. Acta Orthop 2005; 76: 331-335

Eneroth, M., Ohlsson, U-B. \& Thorngren, KG. Insufficient fluid and enegry intake in hospitalised patients with hip fracture. A prospective randomised study of 80 patients. Clin Nutr 2005; 24: 297-303

Beaupre LA, Allyson Jones C, Saunders LD, Johnston DWC, Buckingham J, Majumdar SJ. Best Practices for Elderly Hip Fracture Patients. J Gen Intern Med 2005 Nov;20(11):1019-25 
Pfeiffer EA. A short portable mental status questionnaire of organic brain deficit in elderly patients. J Am Geriatr Soc 1975; 23: 433-441

Braden B, Bergström NA. A conceptual schema for the study of aetiology of pressure sores. Rehabil Nurse 1987;12:8-12

Ek AC, Bjurulf P. Interrater variability in a Modified Norton scale. Scand J Caring Sci, 1987; 1: 99-102

EPUAP. European Pressure Ulcer Advisory Panel. Guidelines on pressure ulcer treatment of pressure ulcers. EPUAP Review, 1999; 1:31-33

Beck, AM. \& Ovesen L. At witch body mass index and degree of weight less should hospitalised elderly patients be considered at nutritional risk? Clin Nutr 1998; 17 (5):195-198

Lipshitz, DK. (1994). Sreening nutritional status in the elderly. Primary Care; 21:55-67.

Dey DK, Rothenberg E., Sundh V, Bosaeus I. Steen B. Height and body weight in the elderly. I. A 25-year longitudinal study of a population aged 70 to 95 years. Eur J Clin Nutr 1999 Dec;53(12):905-14

Symreng, T. Arm anthropometry in a large reference population and in surgical patients. Clin Nutr 1982; 1:211-221

Hedstrom M, Sääf M, Dahlen N. Low IGF-I levels in hip fracture patients. A comparison of 20 coxarthrotic and 23 hip fractre patients. Acta Orthop Scand. 1999 Apr;70(2):145-8

Huusko TM, Karppi P, Avikainen V, Kautianien H, Sulkuva R, Randomized clinically controlled trial of intensive geriatric rehabilitation in patietns with a hip fracture: subgroup analysis of patientes with dementia. BMJ. 2000:321(34ref): 1107-1111

Rolland Y, Pillard F, Lauwers-Canses V, Busquere F Vellas B Lafont,C. Rehabilitation outcome of elderly patients with a hip fracture and cognitive impairment. Disabil Rehabil. 2004: 26: 425-31

Cohen, D. Dementia, depression and nutritional status. Prim Care 1994;21 10719

Kwok t \& Whitelaw MN. The use of armspan in nutritional assessment of elderly, JAGS 1991:39: 492-496

Reed RL, Hepburn K, Adelson R, Center B, McKnight P. Low serum albumin levels, confusion, and fecal incontinence: are these risk factors for pressure ulcers in mobility-impaired hospitalized adults? Gerontology 2003 Jul-Aug;49(4):255-9

Lindgren M, Unosson M, Krantz AM et al. Pressure ulcer risk factors in patients undergoing surgery. J Adv Nurs 2005;50:605-12 
Houwing R, Rozendaal M, Wouters-Wesseling W et al. Pressure ulcer risk in hip fracture patients. Acta Orthop Scand 2004;75:390-393

Tidermark ., Ponzer S, Carlsson P, Söderqvist A, Brismar K, Tengstrand B, Cederholm, T. Effects of protein-rich supplementation and nandrolone in lean elderly women with hip fractures. Clin Nutr 2004; 23:587-596

Avenell, A. \& Handoll, HHG. (2004) Nutritional supplementation for hip fracture aftercare in the elderly. Cochrane Database Systematic Review. Issue 1.

Table 1. European Pressure Advisory Panel's classification of pressure ulcers

Grade I Non-blanchable erythema of intact skin. Discoloration of the skin, warmth, oedema, induration or hardness may also be used as indicators particularly on individuals with dark skin.

Grade II Partial thickness skin loss involving epidermis, dermis or both. The ulcer is superficial and presents clinically as an abrasion or blister.

Grade III Full thickness skin loss involving damage to or necrosis of subcutaneous tissue that may extend down to, but not trough underlying fascia.

Grade IV Extensive destruction, tissue necrosis, or damage to muscle, bone or supporting structures with or without full thickness skin loss. 
Table 2. Biochemical variable on the patietns in the CG and IG.

\begin{tabular}{|c|c|c|c|c|c|c|c|}
\hline $\begin{array}{l}\text { Variable mean } \\
\text { (SD) }\end{array}$ & $\mathrm{n}$ & CG & & $\mathrm{n}$ & IG & & p-value \\
\hline \multicolumn{8}{|l|}{ At baseline } \\
\hline $\mathrm{Hb}$ & 210 & 123.5 & $(16.5)$ & 210 & 123.7 & $(16.0)$ & 0.93 \\
\hline EVF & 176 & 36.7 & $(4.5)$ & 203 & 36.8 & $(4.3)$ & 0.76 \\
\hline $\mathrm{Sd}$ & 210 & 140.6 & $(4.0)$ & 210 & 143,0 & $(19.0)$ & 0.14 \\
\hline PT & 209 & 3.9 & $(0.6)$ & 208 & 36.8 & $(4.3)$ & 0.23 \\
\hline Crea & 202 & 76 & $(32.7)$ & 207 & 80 & $(39.5)$ & 0.27 \\
\hline CRP & 204 & 21.6 & $(34.5)$ & 206 & 25.3 & (44.4) & 0.34 \\
\hline $\mathrm{Fe}$ & 201 & 9.3 & $(5.2)$ & 203 & 9.7 & $(5.1)$ & 0.43 \\
\hline TIBC & 203 & 56 & (11.4) & 204 & 57 & $(10.7)$ & 0.60 \\
\hline Alb & 208 & 36 & $(4.6)$ & 207 & 36 & $(4.1)$ & 0.53 \\
\hline $\mathrm{Ca}$ & 207 & 2.4 & $(0.2)$ & 205 & 2.4 & $(0.1)$ & 0.71 \\
\hline TTR & 197 & 0.21 & $(0.06)$ & 204 & 0.22 & $(0.06)$ & 0.64 \\
\hline \multicolumn{8}{|c|}{ On day 5 postoperatively } \\
\hline $\mathrm{Hb}$ & 199 & 108 & $(14.5)$ & 205 & 107 & $(14.3)$ & 0.42 \\
\hline EVF & 185 & 32.3 & $(4.3)$ & 191 & 32.2 & $(4.2)$ & 0.75 \\
\hline $\mathrm{Sd}$ & 198 & 139 & $(4.6)$ & 199 & 140 & $(4.1)$ & 0.005 \\
\hline PS & 197 & 3.8 & $(0.5)$ & 200 & 3.7 & $0.5)$ & 0.19 \\
\hline \multicolumn{8}{|l|}{ At discharge } \\
\hline $\mathrm{Hb}$ & 202 & 111 & $(13.4)$ & 203 & 111 & $(14.0)$ & 0,7 \\
\hline \multicolumn{8}{|c|}{4 month follow-up } \\
\hline $\mathrm{Hb}$ & 161 & 127 & $(14.0)$ & 163 & 127 & $(12.7)$ & 0.72 \\
\hline EVF & 160 & 38.3 & $(4.0$ & 163 & 38.9 & $(3.7)$ & 0.13 \\
\hline TTR & 170 & 0.25 & $(0.07)$ & 166 & 0.22 & $(0.06)$ & $<0.001$ \\
\hline
\end{tabular}

CG, Control group, IG, Intervention group Haemoglobin, (Hb), hematocrit (EVF), sodium (Sd), potassium (Ps), creatininium $(\mathrm{C}), \mathrm{C}$-reactive protein $(\mathrm{CRP})$, iron $(\mathrm{Fe})$, total iron binding concentration (TIBC), albumin (Alb) and transthyretin (TTR). Data are given as mean. Significances are tested with Student T-Test. 
Table 3. Patients and fracture characteristics.

\begin{tabular}{|c|c|c|c|c|c|}
\hline \multirow{2}{*}{$\begin{array}{l}\text { Characteristics } \\
\text { Age (mean) }\end{array}$} & \multicolumn{2}{|c|}{$\begin{array}{c}\mathbf{C G} \\
\mathrm{n}=210\end{array}$} & \multicolumn{2}{|c|}{$\begin{array}{c}\mathbf{I G} \\
\mathrm{n}=210\end{array}$} & \multirow{2}{*}{$\begin{array}{r}\text { p- } \\
\text { value } \\
\text { ns }\end{array}$} \\
\hline & 81.5 & \pm 10.5 & 80.4 & \pm 10.3 & \\
\hline Female gender & 148 & $(70.5)$ & 140 & $(66.7)$ & ns \\
\hline Lucid patients $(\%)$ & 129 & $(61.4)$ & 136 & $(64.8)$ & ns \\
\hline Not lucid patients $(\%)$ & 81 & $(38.6)$ & 74 & $(35.2)$ & ns \\
\hline SPMSQ (SD) & 6.8 & $(3.8)$ & 7.2 & $(3.4)$ & ns \\
\hline Smoker $(\%)$ & 50 & $(23.8)$ & 43 & $(20.4)$ & ns \\
\hline Cervikal fracture $(\%)$ & 114 & $(54.3)$ & 113 & $(53.8)$ & ns \\
\hline ASA grade, mean (SD) & 2.38 & $(0.7)$ & 2.43 & $(0.8)$ & ns \\
\hline Pathological fracture (\%) & 4 & $(1.9)$ & 5 & $(2.4)$ & ns \\
\hline Median time to surgery, hours (SD) & 26.5 & $(23.6)$ & 27.4 & $(16.3)$ & ns \\
\hline $\begin{array}{l}\text { Median time on operation table (SD) } \\
\qquad(\mathrm{n}=208 \text { in both groups })\end{array}$ & 132.7 & $(39.5)$ & 126.4 & $(39.2)$ & ns \\
\hline Median hospital stay, days (SD) & 10.8 & $(5.8)$ & 11.8 & $(7.4)$ & ns \\
\hline Living in own home $(\%)$ & 140 & $(66.7)$ & 141 & $(67.1)$ & ns \\
\hline Living alone (\%) & 90 & $(42.9)$ & 85 & $(40.5)$ & ns \\
\hline Discharged back to origin $(\%)$ & 114 & $(54.3)$ & 119 & $(56.7)$ & ns \\
\hline Mortality at four months (\%) & 30 & $(14.3)$ & 31 & $(14.8)$ & ns \\
\hline Mortality at 12 months $(\%)$ & 48 & $(22.9)$ & 41 & $(19.5)$ & ns \\
\hline
\end{tabular}

$\mathrm{CG}=$ Control group, $\mathrm{IG}=$ Intervention group

$\mathrm{SPMSQ}=$ Short portable mental status questionnaire

Data presented as mean \pm standard deviation or on $\mathrm{n}(\%)$.

Significance measured with Students T-test or Ficher's exact test 
Table 4. Anthropometric characteristics of the patients in CG and IG

\begin{tabular}{|c|c|c|c|c|c|c|c|}
\hline Variable mean (SD) & $\mathrm{n}$ & & CG & $\mathrm{n}$ & & IG & p-value \\
\hline \multicolumn{8}{|l|}{ At baseline } \\
\hline Height (m) & 202 & 1.63 & $(9.9)$ & 205 & 1.65 & $(9.7)$ & 0.046 \\
\hline Total arm length $(\mathrm{cm})$ & 201 & 56.3 & $(4.0)$ & 205 & 56.9 & $(4.2)$ & 0.146 \\
\hline MAC (cm) & 201 & 28.0 & $(4.7)$ & 204 & 27.4 & $(4.1)$ & 0.158 \\
\hline TSF (mm) & 197 & 14.7 & $(6.7)$ & 204 & 14.9 & $(6.9)$ & 0.739 \\
\hline $\operatorname{AMC}(\mathrm{cm})$ & 197 & 23.3 & $(3.4)$ & 204 & 22.7 & $(3.0)$ & 0.050 \\
\hline $\mathrm{CC}(\mathrm{cm})$ & 201 & 33.7 & $(4.6)$ & 204 & 32.8 & $(3.8)$ & 0.038 \\
\hline Knee height & 201 & 46.8 & $(3.7)$ & 204 & 47.0 & $(3.8)$ & 0.479 \\
\hline Weight (kg) & 202 & 65.6 & $(14.1)$ & 199 & 64.9 & $(12.9)$ & 0.588 \\
\hline BMI $\left(\mathrm{kg} / \mathrm{m}^{2}\right)$ & 201 & 24.7 & $(4.6)$ & 197 & 23.8 & $(4.1)$ & 0.043 \\
\hline \multicolumn{8}{|l|}{ At 4 months } \\
\hline Weight (kg) & 174 & 63.0 & $(13.9)$ & 168 & 62.9 & $(13.8)$ & 0.909 \\
\hline BMI $\left(\mathrm{kg} / \mathrm{m}^{2}\right)$ & 173 & 23.6 & $(4.4)$ & 176 & 22.8 & $(4.3)$ & 0.089 \\
\hline \multicolumn{8}{|l|}{ At 12 months } \\
\hline Weight (kg) & 152 & 35.7 & $(14.7)$ & 146 & 64.3 & (14.2) & 0.413 \\
\hline BMI $\left(\mathrm{kg} / \mathrm{m}^{2}\right)$ & 152 & 24.6 & $(4.6)$ & 145 & 23.4 & $(4.4)$ & 0.021 \\
\hline
\end{tabular}

$\mathrm{CG}=$ Control group, $\mathrm{IG}=$ Intervention group, $\mathrm{MAC}=\mathrm{Mid}$ arm circumference, $\mathrm{CC}=$ Calf circumference, $\mathrm{TSF}=$ Triceps skin fold, $\mathrm{AMC}=\mathrm{Arm}$ muscle circumference, $\mathrm{BMI}=$ Body mass index,

Data presented as mean \pm standars deviation. Significance measured with Students T-test 
Table 5. The total number of pressure ulcers, their location and patients with pressure ulcers at admission, at discharge and hospital acquired

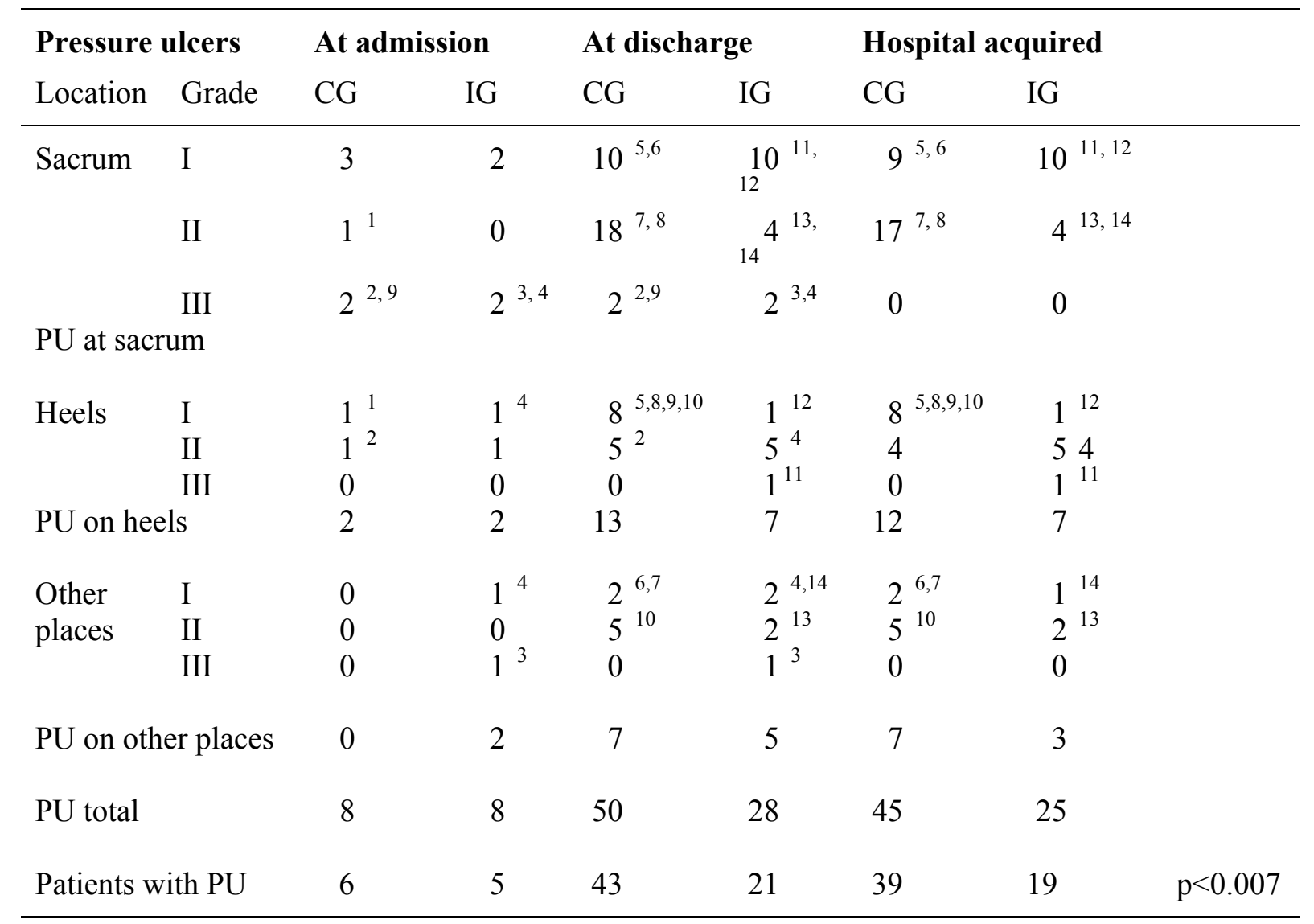

$\mathrm{CG}=$ control group, $\mathrm{IG}=$ intervention group, $\mathrm{PU}=$ pressure ulcers

Patients with more than one pressure ulcer are identified as ${ }^{1-14 .}$ 